\title{
Polydatin Protects Bone Marrow Stem Cells against Oxidative Injury: Involvement of Nrf 2/ARE Pathways
}

\author{
Meihui Chen, Yu Hou, and Dingkun Lin \\ Research Laboratory of Spine Degenerative Disease, Guangdong Provincial Hospital of Traditional Chinese Medicine, \\ Guangzhou 510120, China \\ Correspondence should be addressed to Dingkun Lin; lindingkun@126.com
}

Received 29 April 2015; Revised 20 July 2015; Accepted 2 August 2015

Academic Editor: Kenichi Tamama

Copyright (C) 2016 Meihui Chen et al. This is an open access article distributed under the Creative Commons Attribution License, which permits unrestricted use, distribution, and reproduction in any medium, provided the original work is properly cited.

Polydatin, a glucoside of resveratrol, has been reported to possess potent antioxidative effects. In the present study, we aimed to investigate the effects of polydatin in bone marrow-derived mesenchymal stem cells (BMSCs) death caused by hydrogen peroxide $\left(\mathrm{H}_{2} \mathrm{O}_{2}\right)$, imitating the microenvironment surrounding transplanted cells in the injured spinal cord in vitro. In our study, MTT results showed that polydatin effectively prevented the decrease of cell viability caused by $\mathrm{H}_{2} \mathrm{O}_{2}$. Hochest 33258, Annexin V-PI, and Western blot assay showed $\mathrm{H}_{2} \mathrm{O}_{2}$-induced apoptosis in BMSCs, which was attenuated by polydatin. Further studies indicated that polydatin significantly protects BMSCs against apoptosis due to its antioxidative effects and the regulation of Nrf 2/ARE pathway. Taken together, our results indicate that polydatin could be used in combination with BMSCs for the treatment of spinal cord injury by improving the cell survival and oxidative stress microenvironments.

\section{Introduction}

Among central nervous system (CNS) disorders, spinal cord injury (SCI) is the most devastating and traumatic $[1,2] .40$ cases per million individuals are diagnosed as SCI [3]. Bone marrow-derived mesenchymal stem cells (BMSCs), which possess immunosuppressive properties and the capacity for unlimited self-amplification and for terminal differentiation $[4,5]$, play a privileged role in ameliorating neuronal damage in CNS disease models including SCI [6]. Cellular replacement with MSCs in different SCI animal models has showed functional recovery $[7,8]$. However, attempts to transplant BMSCs into animal and human subjects are hampered mainly due to the poor survival of BMSCs [9]. After being transplanted, BMSCs are facing a complicated environment with risk factors that may lead to cell death including oxidative stress $[4,9,10]$. The increased reactive oxygen species (ROS) resulting in sustained oxidative stress in damaged spinal cord is one of the key factors that challenged the survival of donor BMSCs. BMSCs may unavoidably result in apoptosis under oxidative circumstance. Therefore, drugs with antioxidative effects and antiapoptosis may be crucial for the successful transplantation of BMSCs in SCI [10].
Polydatin (Figure 2(a)), isolated from the roots of Polygonum cuspidatum, is widely used in traditional Chinese remedies [11-14]. Polydatin has been shown to protect heart function, prevent the development of diabetic renal fibrosis, and ameliorate Alzheimer's disease due to its multiple pharmacological actions, such as antioxidation, antiinflammation, immunoregulation, antitumor, and neuroprotection [15-18]. However, the protective activity of polydatin on transplanted BMSCs after SCI is unknown.

In this study, we demonstrated for the first time that polydatin might protect BMSCs against $\mathrm{H}_{2} \mathrm{O}_{2}$-induced apoptosis due to enhancing the resistance of BMSCs against oxidative injury and activate the nuclear factor E2-related factor 2 ( Nrf 2)/antioxidant response element (ARE) pathway, which has been reported to have key roles in regulating endogenous antioxidants and phase II detoxification enzymes, suggesting that polydatin could be a promising approach to increase the cell survival in cell replacement therapy for SCI.

\section{Materials and Methods}

2.1. Materials. Male Sprague-Dawley (SD) rats $(100 \pm 20 \mathrm{~g})$ were supplied by the Center of Experimental Animals, 
Guangzhou University of Chinese Medicine (Guangzhou, China, Certificate number 00100561). All procedures were performed according to animal guidelines of Guangzhou University of Chinese Medicine. Polydatin was purchased in Aladdin (Shanghai, China). Trypsin, 3-(4,5-dimethylthiazol2-yl)-2,5-diphenyltetrazolium bromide (MTT), dimethyl sulfoxide (DMSO), Hochest 33258, and dichlorofluorescein diacetate $\left(\mathrm{H}_{2} \mathrm{DCF}-\mathrm{DA}\right)$ were purchased from Sigma-Aldrich (MO, USA). Low-glucose Dulbecco's modified Eagle's medium (LG-DMEM) and fetal bovine serum (FBS) were obtained from Gibco-BRL (NY, USA). Hydrogen peroxide, lactate dehydrogenase (LDH), Annexin V FITC/PI, CellLight 5-ethynyl-2'-deoxyuridine (EdU) Apollo594 in vitro Image kit, and glutathione (GSH) assay kits were purchased from Keygen (Nanjing, China). Brusatol was bought from Chengdu PureChem-Standard Co., Ltd. (Chengdu, China). Polydatin (Aladdin) was dissolved in DMSO before dilution with the culture medium. The final concentration of DMSO was $0.1 \%$.

2.2. Cell Culture and Treatment. Culture of rat BMSCs was performed as previously described [19]. Briefly, all bone marrow was flushed out with a $10 \mathrm{~mL}$ syringe using LG-DMEM supplemented with $10 \%$ FBS. The whole marrow washouts were collected, centrifuged, and plated into a culture flask in $37^{\circ} \mathrm{C}$ under $5 \% \mathrm{CO}_{2}$. All cells used in the assay were of passages 3-5. The phenotypic properties of BMSCs were identified by flow cytometry as previously reported [20]. Cells were pretreated with polydatin for $2 \mathrm{~h}$ and then treated with $\mathrm{H}_{2} \mathrm{O}_{2}(600 \mu \mathrm{M})$ for $24 \mathrm{~h}$.

2.3. Cell Viability Assay. Cell viability was measured by MTT assay. Cells were plated on 96-well plates at a density of $1 \times$ $10^{4}$ for $24 \mathrm{~h}$. After incubation with $\mathrm{H}_{2} \mathrm{O}_{2}$ for $24 \mathrm{~h}, 10 \mu \mathrm{L}$ MTT $(5 \mathrm{mg} / \mathrm{mL})$ was then added to each well and the mixture was incubated for $3 \mathrm{~h}$ at $37^{\circ} \mathrm{C}$. MTT reagent was then replaced with DMSO (100 $\mu \mathrm{L}$ per well) to dissolve formazan crystals. After the mixture was shaken at $37^{\circ} \mathrm{C}$ for $15 \mathrm{~min}$, absorbance was determined at $570 \mathrm{~nm}$ using a microplate reader. Results were expressed as the percentage of MTT reduction and the absorbance of control cells was set as $100 \%$.

2.4. LDH Release Assay. The cytotoxicity was measured by $\mathrm{LDH}$ release assay. $\mathrm{LDH}$ is a cytoplasmic enzyme retained by viable cells with intact plasma membrane and released from cells with damaged membranes. After the indicated treatment of BMSCs, the medium was collected and assayed for $\mathrm{LDH}$ activity as previously reported [21]. Briefly, the release of $\mathrm{LDH}$ is measured with a coupled enzymatic reaction that results in the conversion of a tetrazolium salt into redcolored formazan, which is correlated with $\mathrm{LDH}$ activity. The formazan was measured with a microplate reader at $450 \mathrm{~nm}$. Results were expressed as the percentage of LDH release and the absorbance of control cells was set as $100 \%$.

2.5. Hochest 33258 Assay. To detect morphological evidence of apoptosis, cell nuclei were visualized by DNA staining with the fluorescent dye Hochest 33258. After treatment, BMSCs were stained with Hochest $33258(1 \mu \mathrm{g} / \mathrm{mL})$ for $15 \mathrm{~min}$ in the dark. Results were tested by visual observation of nuclear morphology through fluorescence microscopy (Olympus, Japan) equipped with a UV filter.

2.6. Annexin V-FITC Assay. The apoptotic ratios of cells were determined with the Annexin V-FITC apoptosis detection kit. Briefly, BMSCs were collected and washed twice with cold PBS buffer, resuspended in $500 \mu \mathrm{L}$ of binding buffer, incubated with $5 \mu \mathrm{L}$ of Annexin V-FITC, conjugated to FITC and $5 \mu \mathrm{L}$ PI for $15 \mathrm{~min}$ at room temperature, and analyzed by flow cytometry I (BD Biosciences). Cells treated with DMSO were used as the negative control.

2.7. Measurement of ROS. Intracellular ROS formation was measured using $\mathrm{H}_{2}$ DCF-DA as reported [22]. Briefly, after treatment, cells were washed with warm PBS three times and then stained with $10 \mu \mathrm{M} \mathrm{H_{2 }}$ DCF-DA in serum-free medium for $30 \mathrm{~min}$ at $37^{\circ} \mathrm{C}$ in the dark. DCF fluorescence was analyzed by visual observation of cell morphology through fluorescence microscopy equipped with a UV filter.

2.8. Detection of Intracellular GSH. Intracellular GSH concentration was tested by a GSH assay kit. By reacting with dithiobis-nitrobenzoic acid, reduced GSH could form a yellow compound, which is quantifiable at $405 \mathrm{~nm}$ and is related to the concentration of the reduced GSH. In brief, whole-cell lysate was prepared according to manufacturer's instructions. The basal contents of GSH in control cells were taken as $100 \%$.

2.9. Cell Proliferation. The proliferation of BMSCs was tested with EdU assay. BMSCs were planted into 6-well plate, and then cells were allowed to adhere for $24 \mathrm{~h}$. After the treatment, BMSCs were incubated with EdU for $4 \mathrm{~h}$ before fluorescent detection. Cells were fixed with $2 \%$ paraformaldehyde for $15 \mathrm{~min}$ and stained with EdU kit according to the manufacturer's instructions. Finally, cells were placed under a laser-scanning confocal microscope (LSM710, Carl Zeiss, Germany) for image acquisition.

2.10. Western Blot Analysis. Western blotting analysis was performed as previously described [22]. In brief, cellular protein was collected and lysed in lysis buffer. The protein concentration was measured using the BCA assay (Keygen, Nanjing, China). Equal amounts of total protein were separated on SDS-PAGE gel and transferred onto the PVDF membranes (Millipore, Billerica, MA). After blocking with 5\% skim milk, the membranes were incubated with primary antibodies Bcl2, Bax, Nrf 2, and NQO-1 (Cell Signaling Technology, Beverly, MA, USA) overnight at $4^{\circ} \mathrm{C}$, followed by sequential incubation with horseradish peroxidase-conjugated secondary antibodies for $2 \mathrm{~h}$. The bands were visualized by an enhanced chemiluminescence detection kit (ECL, Amersham Arlington Heights, IL, USA) and exposed to gel imaging system. The intensities of bands were performed using Quantity One Software (Bio-Rad, Hercules, CA). 


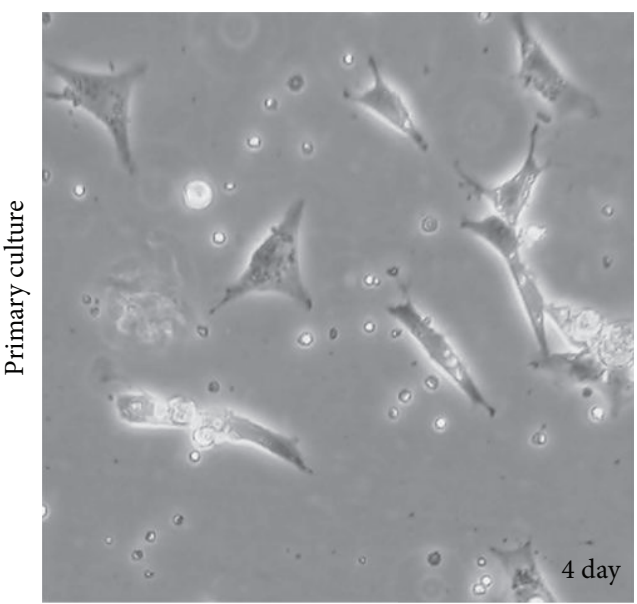

(a)

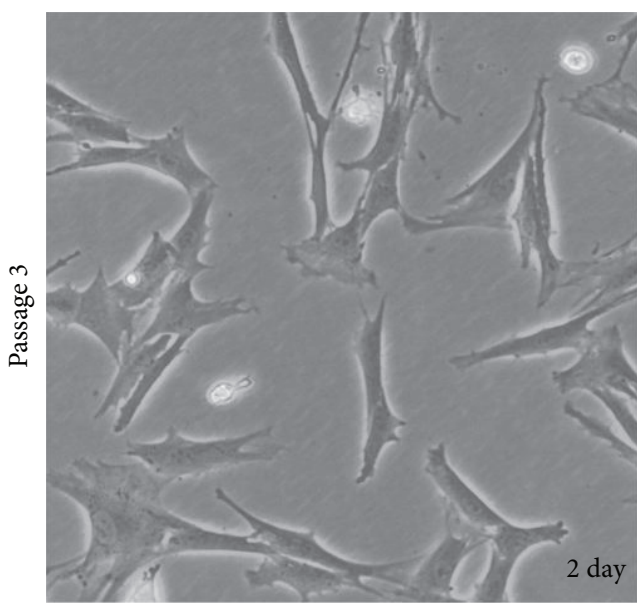

(c)

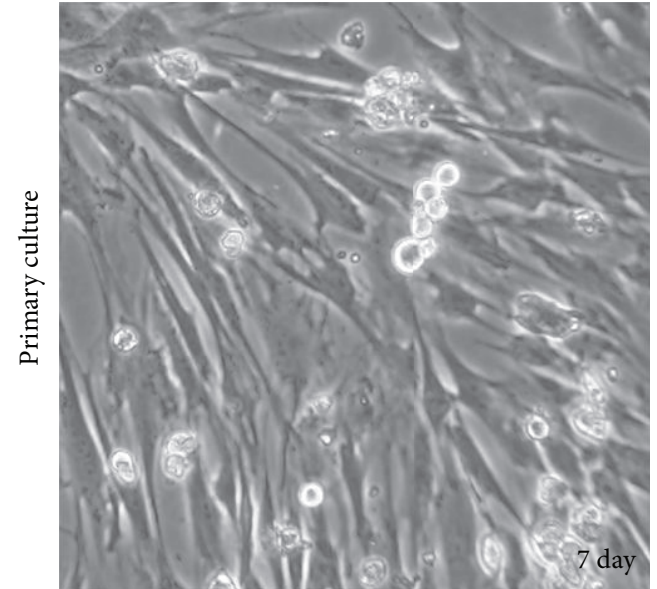

(b)

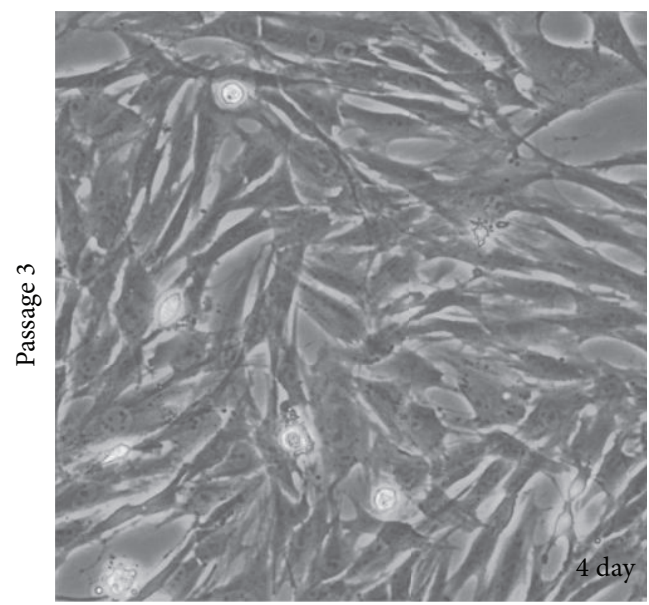

(d)

FIGURE 1: Representative fields of BMSCs morphologies.

2.11. Statistical Analysis. The data were presented as mean \pm S.E.M. Statistical analyses between two groups were performed by unpaired Student's $t$-test. Differences among groups were tested by one-way analysis of variance (ANOVA). A probability value of $p<0.05$ was accepted to be statistically significant.

\section{Results}

3.1. Characterization of BMSCs. BMSCs were isolated from rat bone marrow, expanded in primary culture and passaged for three times. At initial phase, BMSCs of growth contained attached spindle-shaped cells with colonies and floating cells (Figure 1(a)), reaching confluence at day 7 (Figure 1(b)). The floating cells were completely abolished at passage 3 (Figures $1(\mathrm{c})$ and $1(\mathrm{~d}))$.

3.2. Effects of Polydatin on BMSCs Exposed to $\mathrm{H}_{2} \mathrm{O}_{2}$. The viability of BMSCs treated with $\mathrm{H}_{2} \mathrm{O}_{2}$, ranging from 400 to $800 \mu \mathrm{M}$ for $24 \mathrm{~h}$, decreased dose-dependently. $600 \mu \mathrm{M} \mathrm{H}_{2} \mathrm{O}_{2}$ caused approximately cell death by $50 \%$ (Figure 2(b)) and the concentration was chosen for the following experiments. To investigate the effects of polydatin on $\mathrm{H}_{2} \mathrm{O}_{2}$-induced cell death, MTT and LDH assays were applied. The results showed that polydatin significantly increased cell viability (Figures $2(\mathrm{c})$ and $2(\mathrm{~d})$ ) and decreased cell death (Figure 2(e)).

3.3. Polydatin Reduced $\mathrm{H}_{2} \mathrm{O}_{2}$-Induced Apoptosis-Like Cell Death. Hochest 33258 staining and Annexin V-propidium iodide (PI) staining assay were used to observe whether $\mathrm{H}_{2} \mathrm{O}_{2}$ induced apoptotic death. Our results showed that $\mathrm{H}_{2} \mathrm{O}_{2}$ induced nuclear condensation (Figure 3(a)), which was blocked by polydatin. The total apoptotic rate (total rate of the cells that are Annexin V positive and PI positive) of $\mathrm{H}_{2} \mathrm{O}_{2}$ group $(10.95 \% \pm 1.25)$ was significantly increased compared with control group $(4.45 \% \pm 0.15)$, and polydatin effectively reduced the apoptotic rate $(5.15 \% \pm 0.75)$ (Figures $3(\mathrm{~b})$ and $3(c))$. Furthermore, after treatment with $\mathrm{H}_{2} \mathrm{O}_{2}$, upregulation of proapoptotic protein Bax and cleaved caspase- 3 and downregulation of antiapoptotic protein $\mathrm{Bcl}-2$ were observed in BMSCs, which were reversed by polydatin pretreatment. 
<smiles>COc1cc(O)cc(/C=C/c2ccc(O)cc2)c1</smiles>

(a)
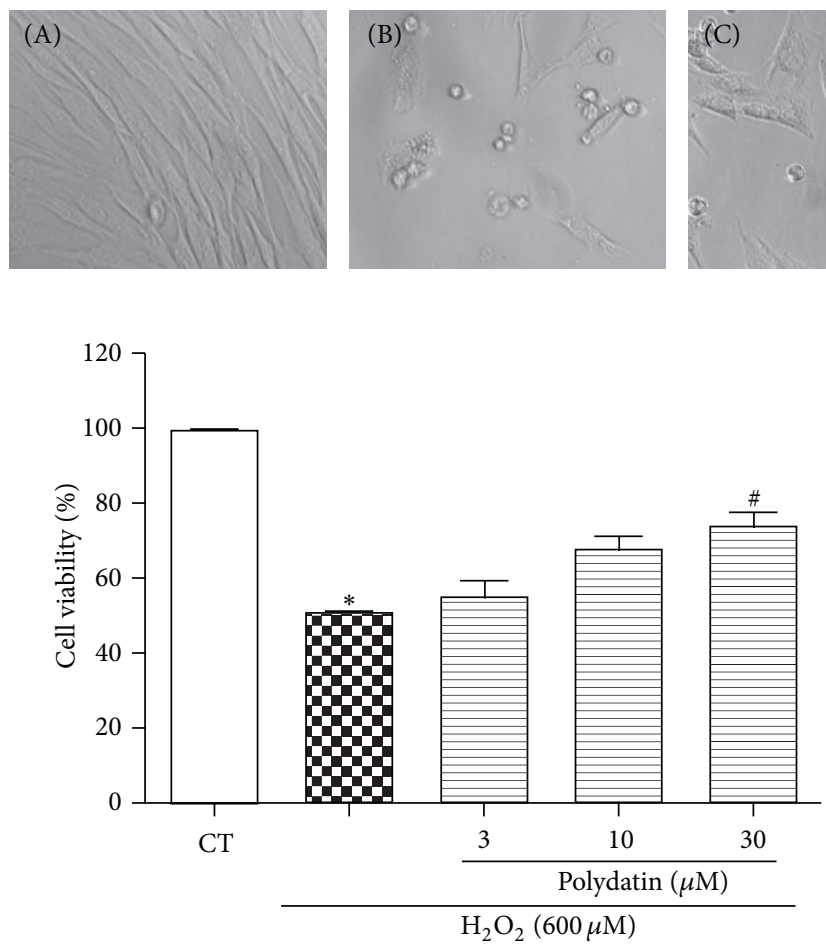

(d)

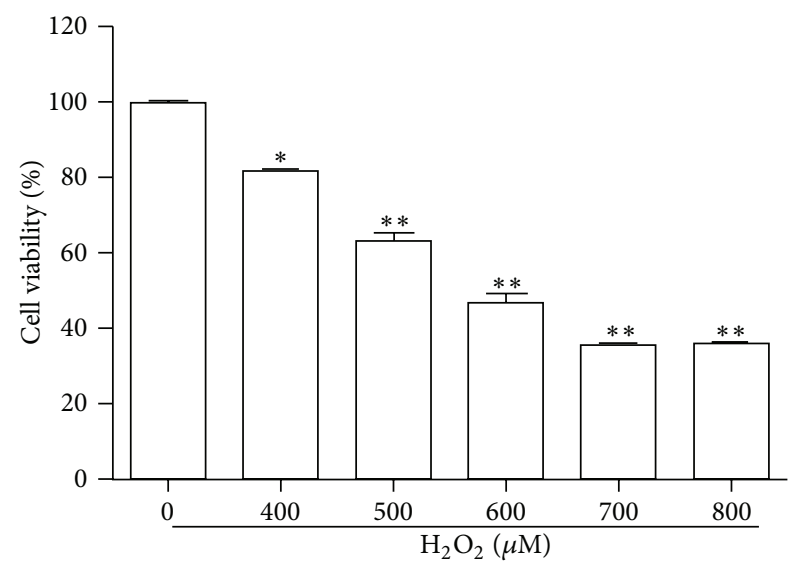

(b)
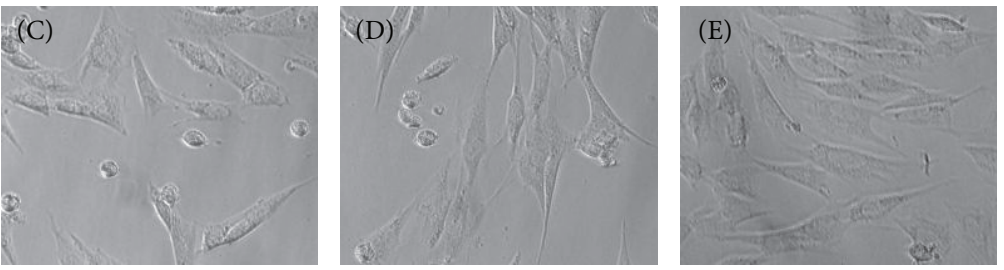

(c)

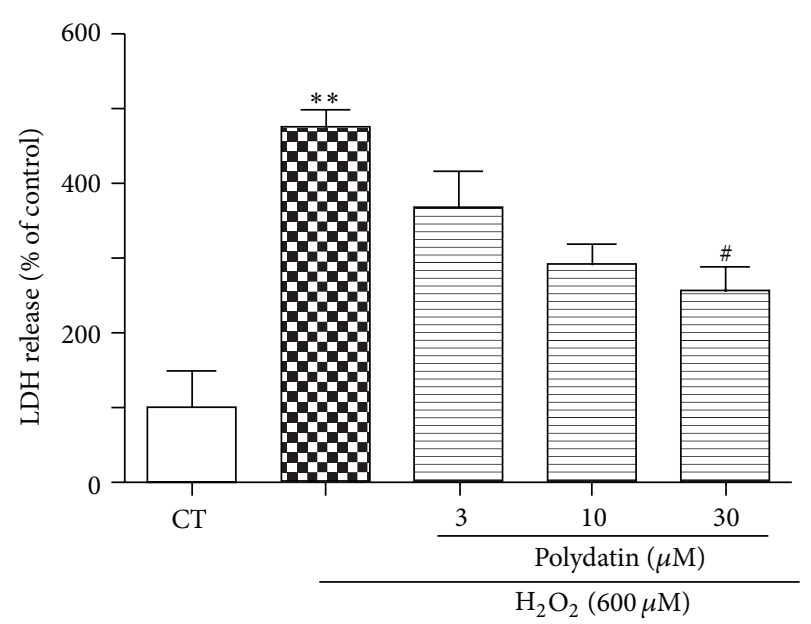

(e)

FIGURE 2: Effects of polydatin on the cell viability of BMSCs exposed to $\mathrm{H}_{2} \mathrm{O}_{2}$. Cells were pretreated with different concentrations of polydatin for $2 \mathrm{~h}$ followed with $\mathrm{H}_{2} \mathrm{O}_{2}(600 \mu \mathrm{M})$ for $24 \mathrm{~h}$. (a) Structure of polydatin. (b) Cells were treated with different concentrations of $\mathrm{H}_{2} \mathrm{O}_{2}$ for 24 h. (c, d) Cell viability was measured by MTT assay and cells were photographed under phase-contrast optics. (A) CT, (B) $\mathrm{H}_{2} \mathrm{O}_{2},(\mathrm{C})$ polydatin $3 \mu \mathrm{M}+\mathrm{H}_{2} \mathrm{O}_{2}$, (D) polydatin $10 \mu \mathrm{M}+\mathrm{H}_{2} \mathrm{O}_{2}$, and (E) polydatin $30 \mu \mathrm{M}+\mathrm{H}_{2} \mathrm{O}_{2}$. (e) Cell death was measured by LDH assay. Bar graph represents independent experiments, each performed in triplicate. One-way ANOVA followed by Tukey's test. Data are presented as means \pm S.D. ${ }^{*} p<0.05$ and ${ }^{* *} p<0.01$ versus control group. ${ }^{*} p<0.05$ versus $\mathrm{H}_{2} \mathrm{O}_{2}$-treated group.

3.4. Polydatin Decreased the Intracellular ROS Formation. To further disclosure the protective mechanism of polydatin, we detected its effects on the formation of intracellular ROS by $\mathrm{H}_{2}$ DCF-DA staining, a ROS probe, and the endogenous antioxidant glutathione (GSH) using a GSH assay kit. As shown in Figures 4(a) and 4(b), compared with the control group, $\mathrm{H}_{2} \mathrm{O}_{2}$-treated group cause significant increase of ROS, which was attenuated by polydatin. Moreover, polydatin also improve the intracellular GSH which was depleted by $\mathrm{H}_{2} \mathrm{O}_{2}$ (Figure 4(c)).

3.5. Effects of Polydatin on the Cell Cycle of BMSCs. It is reported that polydatin, the natural precursor of resveratrol, inhibits proliferation of tumor cells caused by the cell cycle arrest $[23,24]$. Thus, the survival effect of polydatin indicated in the study might simply be a switch of MSCs into 

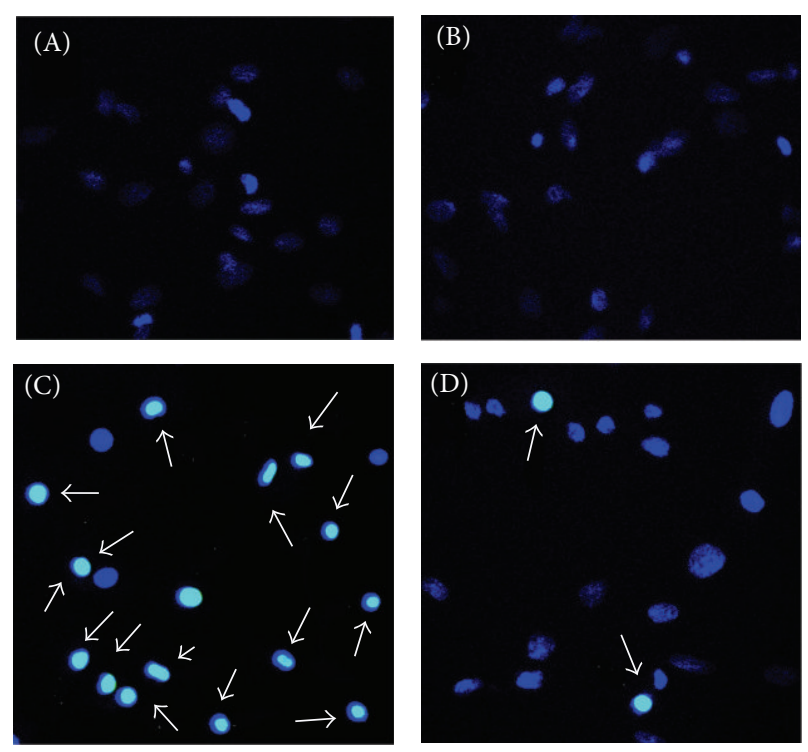

(a)

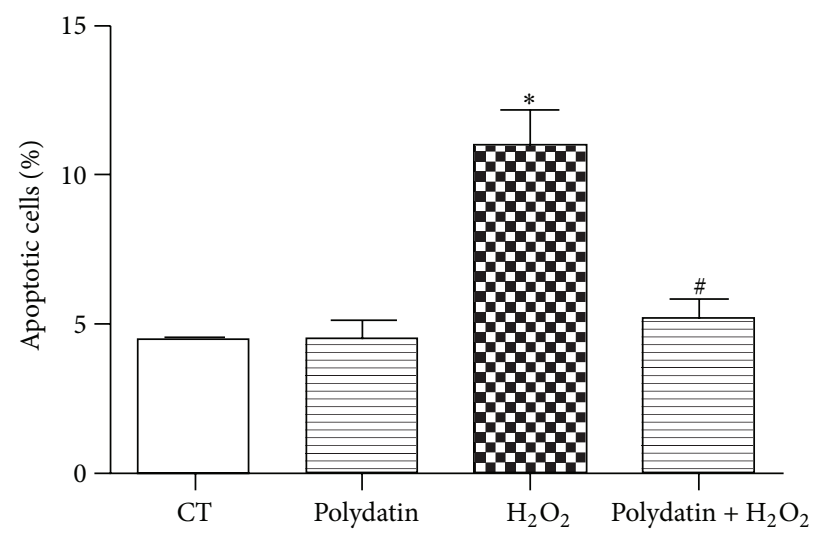

(c)
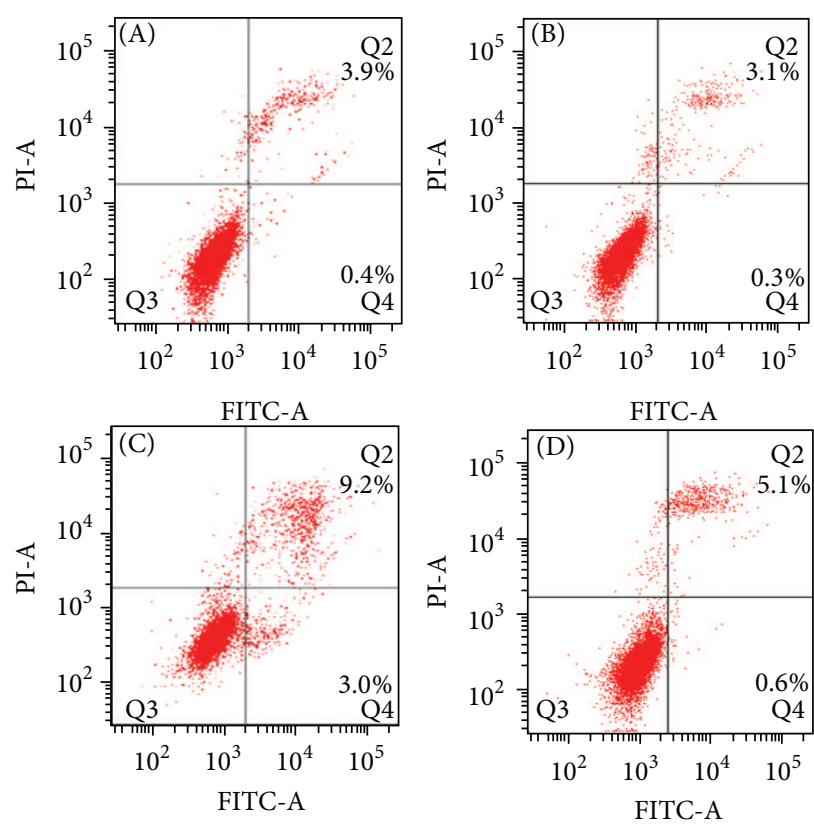

(b)

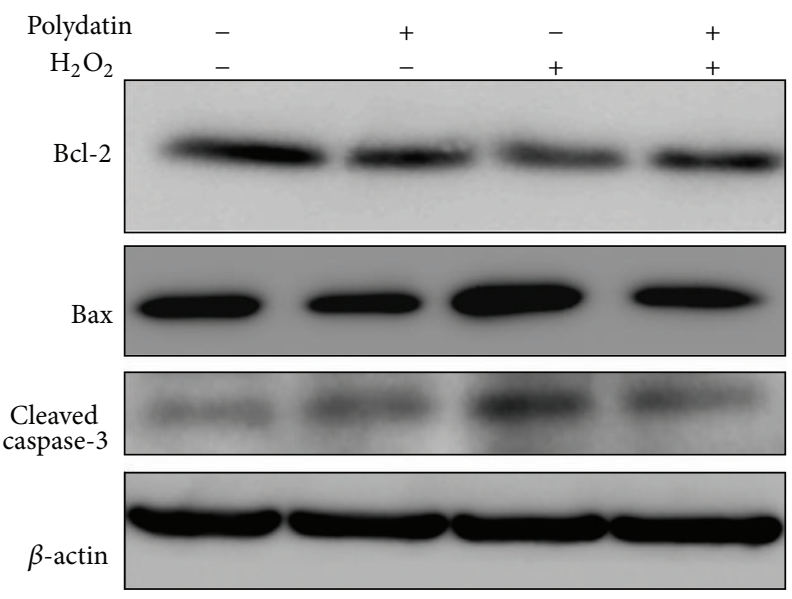

(d)

FIGURE 3: Polydatin attenuated $\mathrm{H}_{2} \mathrm{O}_{2}$-induced apoptosis in BMSCs. (a) Hochest 33258 staining was applied to detect the nuclear condensation of BMSCs, pretreated with polydatin in presence of $\mathrm{H}_{2} \mathrm{O}_{2}$. Fluorescence images (A-D) were observed by fluorescence microscope. (A)(D) represented CT, polydatin, $\mathrm{H}_{2} \mathrm{O}_{2}$, and $\mathrm{H}_{2} \mathrm{O}_{2}+$ polydatin group, respectively. (b) BMSCs were pretreated with $30 \mu \mathrm{M}$ polydatin for $2 \mathrm{~h}$ and followed by exposing to $\mathrm{H}_{2} \mathrm{O}_{2}(600 \mu \mathrm{M})$ for $12 \mathrm{~h}$. The induction of apoptosis was determined using Annexin V-FITC/PI staining. (c) Quantitative analysis of apoptotic cells in Figure 3(b). (d) The expression of Bcl-2, cleaved caspase-3, and Bax of $\mathrm{BMSCs}$ exposed to $\mathrm{H}_{2} \mathrm{O}_{2}$ with or without polydatin. Data are presented as means \pm S.D. ${ }^{*} p<0.05$ versus control group; ${ }^{*} p<0.05$ versus $\mathrm{H}_{2} \mathrm{O}_{2}$-treated group.

quiescence. To examine whether the protective effects are related to polydatin cell cycle arrest activities, EdU assay was applied. Our results showed that $\mathrm{H}_{2} \mathrm{O}_{2}$ significantly reduced the proliferation rate of BMSCs compared with control group; polydatin at $30 \mu \mathrm{M}$ did not cause proliferation inhibition on BMSCs, which suggests that polydatin may not lead to cell cycle arrest on BMSCs at the concentration (Figure 5).

3.6. Polydatin Prevented BMSCs from $\mathrm{H}_{2} \mathrm{O}_{2}$-Induced Apoptosis through Nrf 2/ARE Pathway. Polydatin has been reported to quench ROS overproduction by activating Nrf 2/ARE pathway, which has been reported to have key roles in regulating a battery of endogenous antioxidants and phase II detoxification enzymes, including $\mathrm{NAD}(\mathrm{P}) \mathrm{H}$ quinone oxidoreductase1 (NQO-1) [25]. To explore whether Nrf 2/ARE pathway was involved in the protection of polydatin against oxidative injury, Western blotting was applied. As shown in Figures 6(a)-6(c), $\mathrm{H}_{2} \mathrm{O}_{2}$ significantly decreased the protein levels of p-Nrf 2 and NQO-1 protein, which was partly reversed by polydatin. 

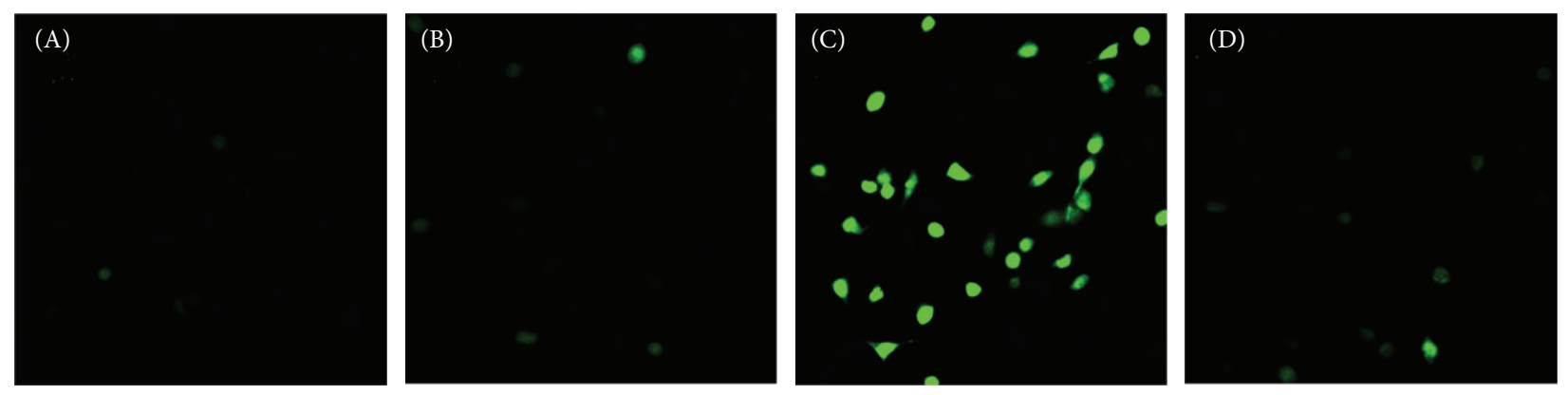

(a)

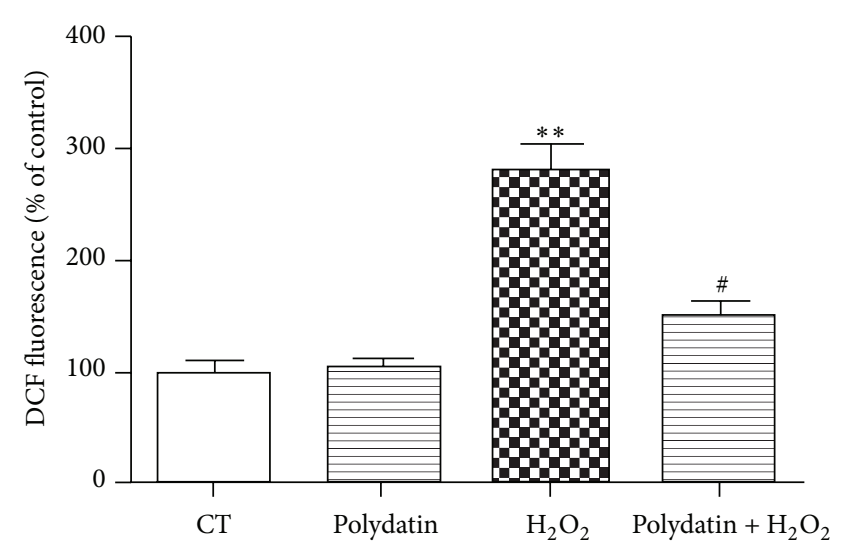

(b)

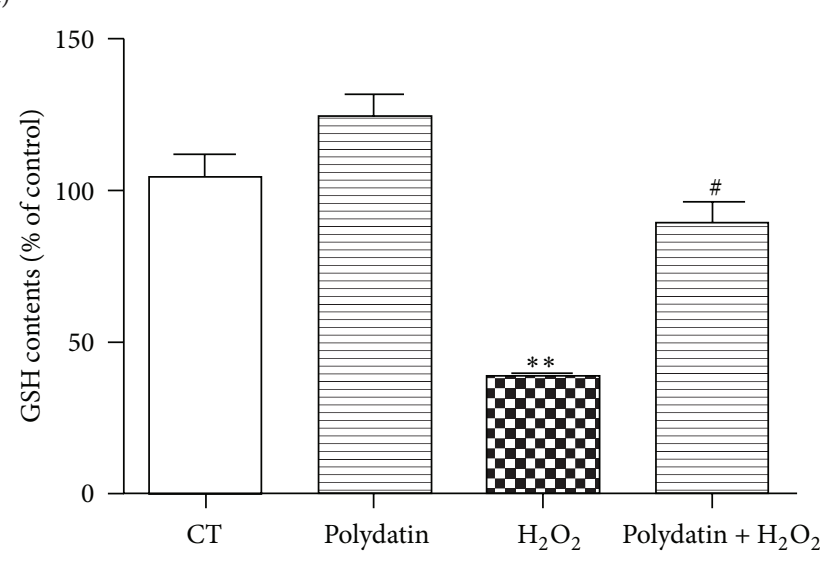

(c)

FIgURE 4: Polydatin scavenges ROS produced by $\mathrm{H}_{2} \mathrm{O}_{2}$. (a) ROS production induced by $\mathrm{H}_{2} \mathrm{O}_{2}$ was detected by $\mathrm{H}_{2}$ DCF-DA staining. (b) Quantitative analysis of DCF fluorescent intensity. (c) The level of GSH was measured using GSH assay kit. The basal contents of GSH in untreated control cells were taken as $100 \%$. Data are collected from 3 independent experiments and presented as means \pm S.D. One-way ANOVA followed by Tukey's test. ${ }^{*} p<0.05$ and ${ }^{* *} p<0.001$ versus control group; ${ }^{*} p<0.05$ versus $\mathrm{H}_{2} \mathrm{O}_{2}$-treated group.

To further confirm the involvement of Nrf 2/ARE pathway in the protective effects of polydatin, brusatol, a unique inhibitor of the Nrf 2 pathway, which selectively reduces the protein level of Nrf 2 through enhanced degradation and ubiquitination of $\operatorname{Nrf} 2$, was applied [26, 27]. As shown in Figure 6(d), brusatol at $100 \mathrm{nM}$ significantly reduced phosphorylation of Nrf 2 and did not cause cell death in BMSCs. Therefore, the concentration was chosen for the next experiment. Our results showed that polydatin attenuated cell viability decrease caused by $\mathrm{H}_{2} \mathrm{O}_{2}$, which was reversed by brusatol (Figure 6(h)). Moreover, brusatol also blocked the ROS scavenging activities of polydatin (Figures 6(f) and 6(i)).

\section{Discussion}

To the best of our knowledge, this is the first report about the effects of polydatin on the oxidative injury induced by $\mathrm{H}_{2} \mathrm{O}_{2}$ in BMSCs. We observed that polydatin dramatically attenuated $\mathrm{H}_{2} \mathrm{O}_{2}$-induced ROS generation, GSH depletion, $\mathrm{LDH}$ release, and subsequent cell death. Further studies showed that polydatin also enhanced phosphorylation of $\mathrm{Nrf} 2$ and upregulation of NQO-1 which was downregulated by $\mathrm{H}_{2} \mathrm{O}_{2}$, suggesting that polydatin might protect BMSCs against $\mathrm{H}_{2} \mathrm{O}_{2}$ partly via $\mathrm{Nrf}$ 2/ARE pathway.
BMSCs, which are capable of self-renewal and differentiation into a variety of mesodermal cell lineages, including osteocytes, chondrocytes, myoblasts, and adipocytes [28, 29] are considered as an ideal source of cells for cell replacement therapy. BMSCs transplantation has shown great promises for treating vast CNS disorders, including SCI. However, poor viability of transplanted BMSCs in injured spinal cord has limited the therapeutic efficiency. Oxidative stress is one of the key mechanisms underlying the pathogenesis of CNS disorders including SCI. Sustained oxidative stress could reduce the survival of donor BMSCs, causing limited reparative capacity of BMSCs. Therefore, it is rational to improve the poor oxidative environment and protect the BMSCs against oxidative stress for the successful transplantation of BMSCs in SCI.

Polydatin, an active stilbene compound isolated from the roots of Polygonum cuspidatum Sieb. and Zucc., has been shown to prevent the development of diabetic renal fibrosis, ameliorate Alzheimer's disease, and protect ischemia/ reperfusion damage in heart and diabetic nephropathy. It has also been reported to have antiapoptosis and antioxidation activities in many cellular systems. However, protective effects of polydatin on BMSCs are unknown. We used $\mathrm{H}_{2} \mathrm{O}_{2}$ to induce oxidative injury on BMSCs, imitating the 

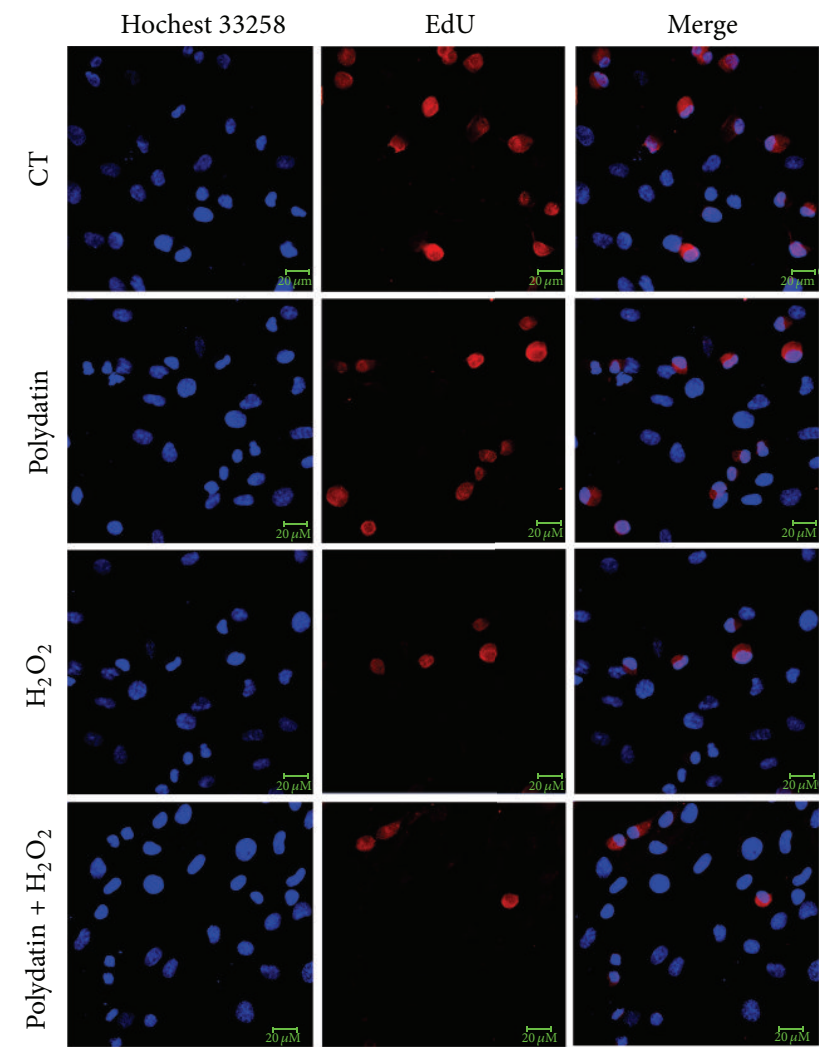

(a)

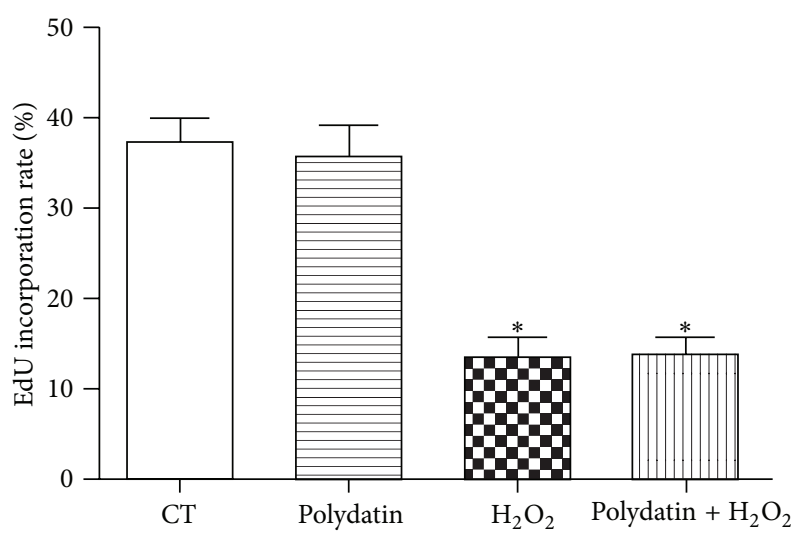

(b)

Figure 5: Polydatin did not inhibit the proliferation of BMSCs. (a) Proliferation rate of BMSCs was detected by EdU and Hochest 33258 staining. Fluorescence was visualized by a laser-scanning confocal microscope. Scale bar represents $20 \mu \mathrm{M}$. (b) Quantitative analysis of the EdU incorporation rate of BMSCs. ${ }^{*} p<0.05$ versus control group.

poor microenvironment of the spinal cord after SCI. Our results showed that $\mathrm{H}_{2} \mathrm{O}_{2}$ reduced cell viability of BMSCs dose-dependently and caused a robust ROS generation and GSH depletion as previously reported [10]. Polydatin, at a concentration of $30 \mu \mathrm{M}$, effectively suppressed $\mathrm{H}_{2} \mathrm{O}_{2}$ induced cell death, scavenged the ROS, and reversed the depletion of GSH, indicating that polydatin exerts beneficial effects on BMSCs as well.

Bcl-2 and Bax are two members of the Bcl-2 family, which are crucial regulatory factors in apoptosis. Bcl-2, the antiapoptotic protein, inhibits apoptosis by preventing cytochrome c release into the cytoplasm [22], while Bax, the proapoptotic protein, promotes apoptosis by inducing mitochondrial membrane depolarization. The $\mathrm{Bcl}-2$ family maintains mitochondrial stabilization by mediating the Bcl2/Bax balance [30]. Caspase-3 is a pivotal executioner caspase, which triggers the cleavage of a number of proteins and ultimately leads to DNA fragmentation, and has long been considered as a key protease involved in cell apoptosis [31]. In the present study, we examined the underlying mechanism of the protection of polydatin against $\mathrm{H}_{2} \mathrm{O}_{2}$-induced apoptosis by detecting the expression of apoptosis-related proteins using Western blot. We observed the upregulation of Bax and cleaved caspase- 3 and downregulation of Bcl-2 following treatment of $\mathrm{H}_{2} \mathrm{O}_{2}$, which were overtly reversed by polydatin, suggesting its antiapoptotic effects.

It is well established that polydatin (also named piceid) and resveratrol inhibit proliferation of tumor cells caused by the cell cycle arrest $[23,24]$. Thus, the survival effect of polydatin indicated in the study might simply be a switch of MSCs into quiescence. To examine whether the protective effects are related to polydatin cell cycle arrest activities, we detected the proliferation rate of BMSCs pretreated with polydatin in the presence or absence of $\mathrm{H}_{2} \mathrm{O}_{2}$ using EdU assay. The results showed that polydatin at $30 \mu \mathrm{M}$ did not cause proliferation inhibition on BMSCs, which suggests that polydatin may not lead to cell cycle arrest on BMSCs at the concentration. According to $\mathrm{Su}$ et al., polydatin induced the cell cycle arrest in the S phase at $300 \mu \mathrm{M}$ on MDA-MB-231 cells but not MCF-7 cells and HepG2 cells, suggesting that polydatin only cause proliferation inhibition in certain cell lines at proper concentrations [23]. According to $\mathrm{Su}$ et al., polydatin protected MDA-MB-231 cells against $\mathrm{H}_{2} \mathrm{O}_{2}$ toxicity at $50 \mu \mathrm{M}$, a concentration which did not cause cell cycle arrest, indicating that the protective effects of polydatin were independent from its effects on cell cycle arrest. Therefore, the protective effects of polydatin reported in our paper may be just related to its antioxidative activities.

Nrf 2, a basic leucine zipper transcription factor, is reported to drive transcription of all kinds of genes involved in combating products of oxygen radicals and oxidation such as protein and DNA adducts from carbonyls or malondialdehyde $[25,32]$. Under normal conditions, Nrf 2 binds to Kelchlike ECH associated protein-1 (Keap1) [33]. When oxidative stress occurs, Nrf 2 is released from Keap1, is translocated to the nucleus, is bound with ARE sequences, and results in transcriptional activation of antioxidant genes including NAD(P)H quinone oxidoreductase-1 (NQO-1) [34]. Huang et al. have reported that polydatin activated Nrf 2/ARE pathway in glomerular mesangial cells [16]. Herein, we found that $\mathrm{H}_{2} \mathrm{O}_{2}$ downregulated NQO-1 and the phosphorylation of Nrf 2 which was partly reversed by polydatin. To further confirm the involvement of $\mathrm{Nrf}$ 2/ARE pathway in the protection of polydatin, brusatol was applied. Previous studies reported 

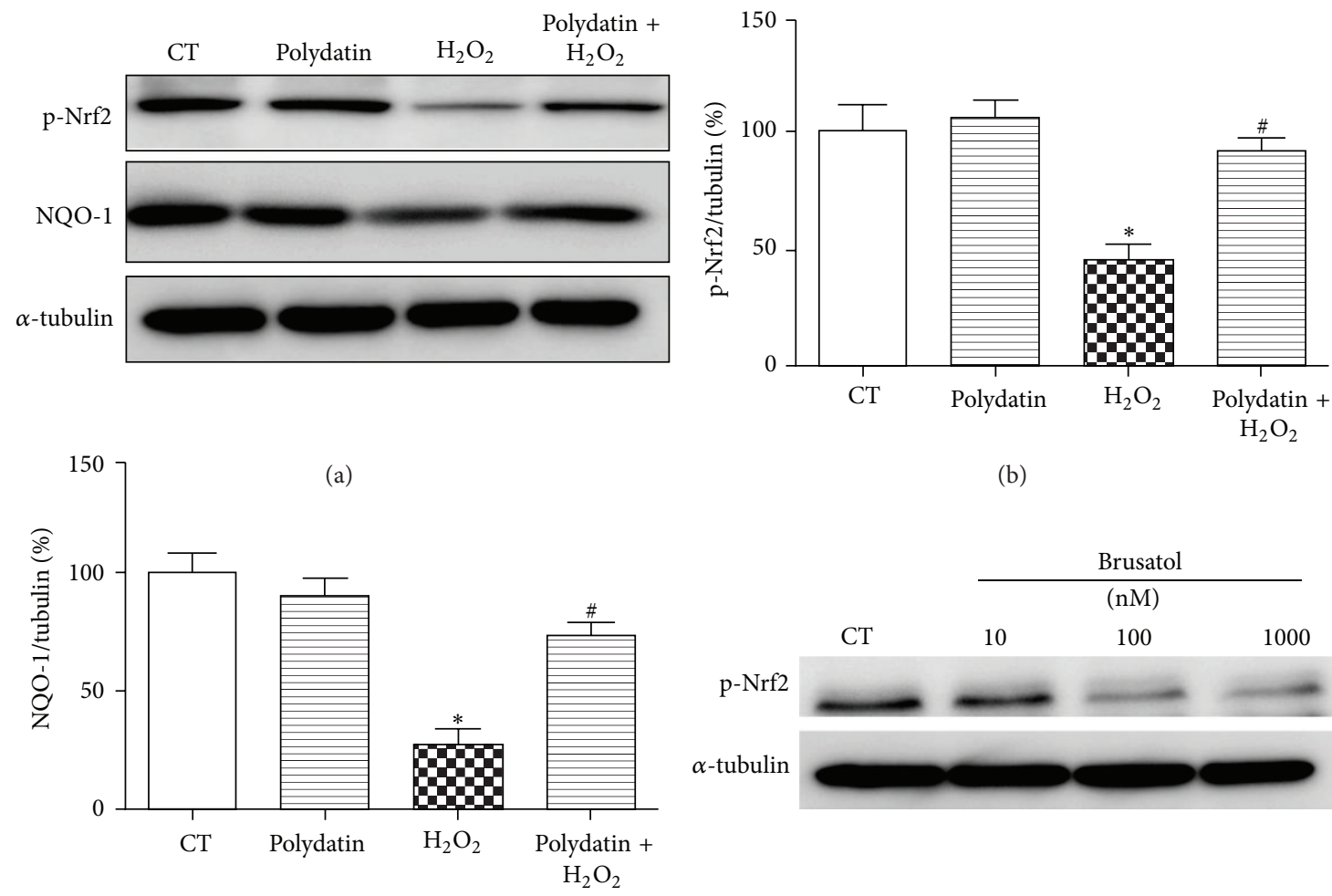

(b)
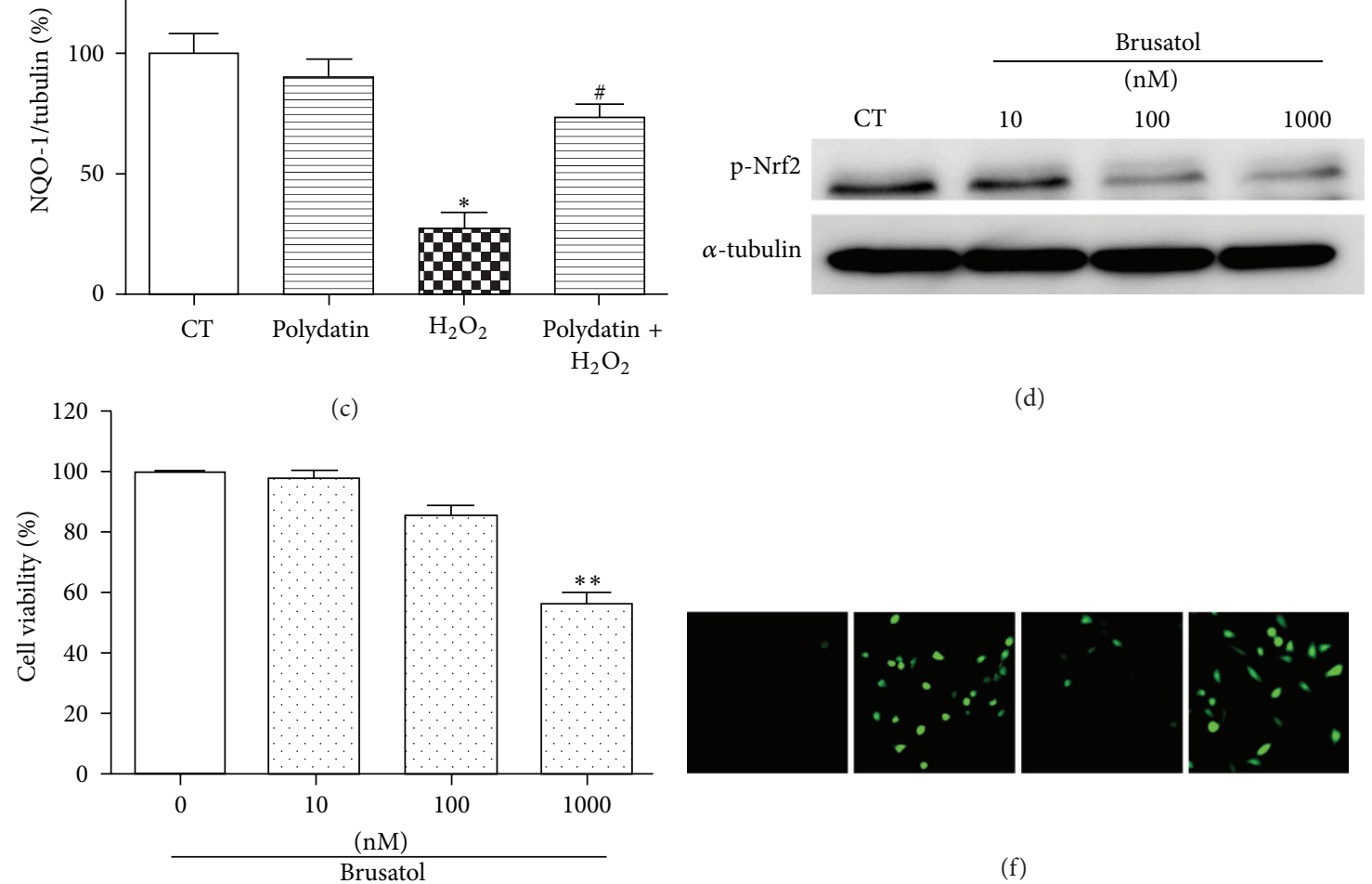

(d)
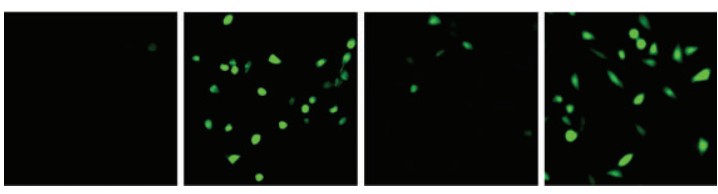

(e)
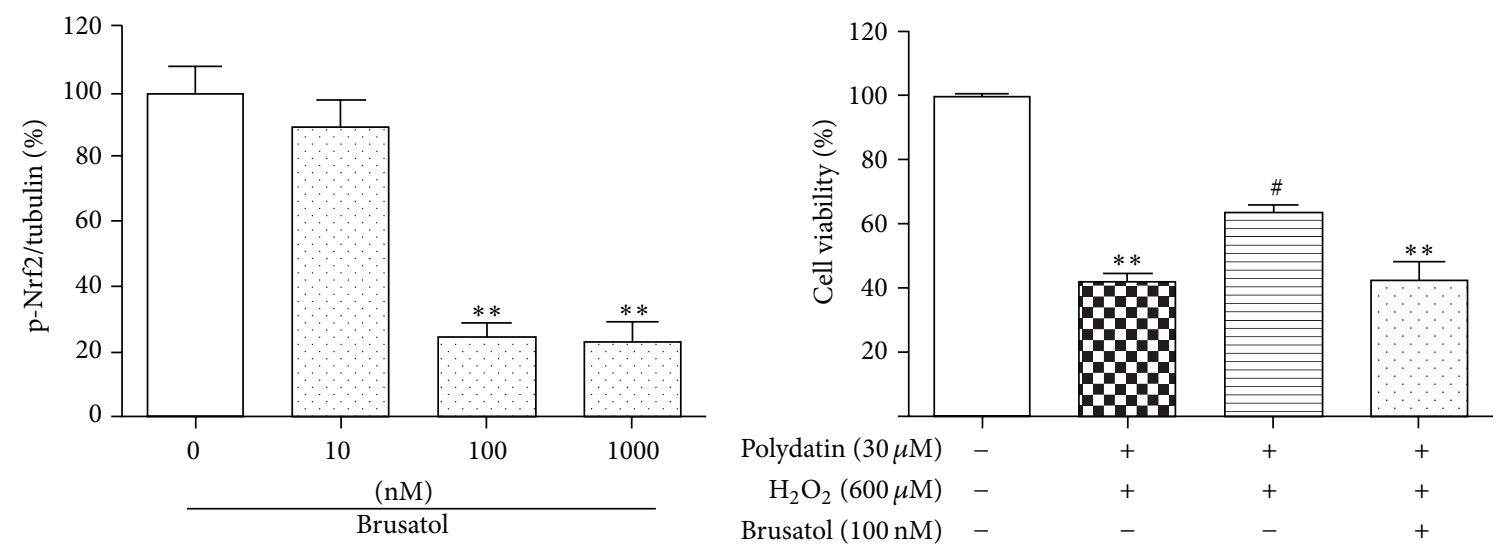

(g)

(h)

Figure 6: Continued. 


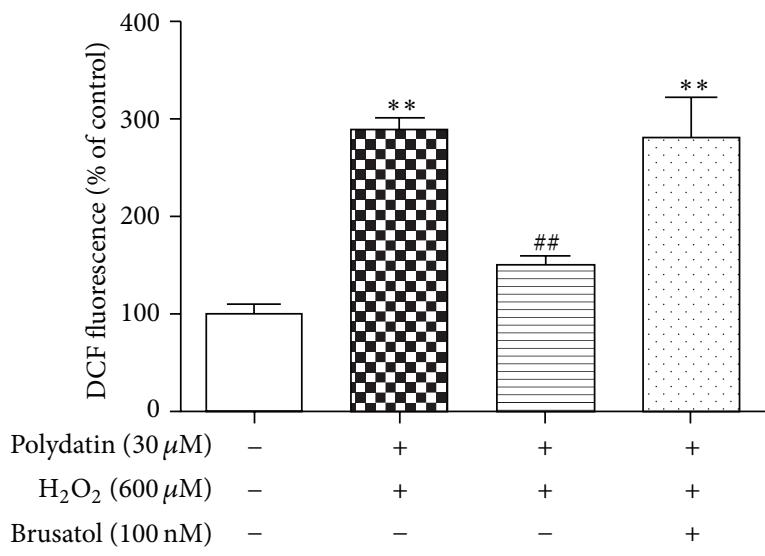

(i)

FIgURE 6: Polydatin protected BMSCs against $\mathrm{H}_{2} \mathrm{O}_{2}$-induced cell death partly through Nrf 2/ARE pathway. BMSCs were pretreated with polydatin for $2 \mathrm{~h}$ and further exposed to $\mathrm{H}_{2} \mathrm{O}_{2}$ for $12 \mathrm{~h}$. (a) Effects of polydatin on NQO-1 and the phosphorylation of Nrf 2. (b, c) Quantitative analysis of the blots was shown in panel after being normalized by $\alpha$-tubulin. (d) Cells were treated with different concentration of brusatol for $24 \mathrm{~h}$. Effects of brusatol on phosphorylation of Nrf 2 were detected by Western blot and (g) the bands were normalized by $\alpha$-tubulin. (e) Cell viability was tested in the presence of different concentration of brusatol. (h) BMSCs were pretreated with brusatol (100 $\mu \mathrm{M})$ for $1 \mathrm{~h}$ followed by incubating with/without polydatin and $\mathrm{H}_{2} \mathrm{O}_{2}$ for $24 \mathrm{~h}$. (f) ROS production was detected by H2DCF-DA staining. (b) Quantitative analysis of DCF fluorescent intensity. One-way ANOVA followed by Tukey's test. ${ }^{*} p<0.05$ and ${ }^{* *} p<0.001$ versus control group; ${ }^{*} p<0.05$ and ${ }^{\# \#} p<0.01$ versus $\mathrm{H}_{2} \mathrm{O}_{2}$-treated group.

brusatol as a unique inhibitor of the Nrf 2 pathway, which selectively downregulates the protein level of Nrf 2 via increasing ubiquitination and degradation of $\operatorname{Nrf} 2$ [27]. Herein, we proved that coincubation with polydatin and brusatol reversed the protective and the ROS scavenging effects of polydatin, suggesting that Nrf 2/ARE pathway was involved in the protection and antioxidation of polydatin against $\mathrm{H}_{2} \mathrm{O}_{2}$-induced cell death.

\section{Conclusion}

Taken together, our results indicate that polydatin exerts strikingly protective effects against $\mathrm{H}_{2} \mathrm{O}_{2}$-induced cytotoxicity in BMSCs through activating the Nrf 2/ARE pathway, suggesting that polydatin could be a promising approach to increase the cell survival in cell replacement therapy for SCI.

\section{Conflict of Interests}

The authors declare that there is no conflict of interests regarding the publication of this paper.

\section{Acknowledgment}

This study was supported by National Natural Science Foundation of China (no. 81273782) to Dingkun Lin.

\section{References}

[1] H. L. Harkey III, E. A. White IV, R. E. Tibbs Jr., and D. E. Haines, "A clinician's view of spinal cord injury," Anatomical Record Part B: New Anatomist, vol. 271, no. 1, pp. 41-48, 2003.
[2] T. K. Ng, V. R. Fortino, D. Pelaez, and H. S. Cheung, "Progress of mesenchymal stem cell therapy for neural and retinal diseases," World Journal of Stem Cells, vol. 6, no. 2, pp. 111-119, 2014.

[3] A. Singh, L. Tetreault, S. Kalsi-Ryan, A. Nouri, and M. G. Fehlings, "Global prevalence and incidence of traumatic spinal cord injury," Clinical Epidemiology, vol. 6, pp. 309-331, 2014.

[4] H.-Y. Chen, X. Zhang, S.-F. Chen et al., "The protective effect of 17beta-estradiol against hydrogen peroxide-induced apoptosis on mesenchymal stem cell," Biomedicine \& Pharmacotherapy, vol. 66, no. 1, pp. 57-63, 2012.

[5] R. Ju, W. Zeng, R. Wu, and Z. Feng, "Interaction between neural stem cells and bone marrow derived-mesenchymal stem cells during differentiation," Biomedical Reports, vol. 3, no. 2, pp. 242-246, 2015.

[6] M. Bacigaluppi, S. Pluchino, G. Martino, E. Kilic, and D. M. Hermann, "Neural stem/precursor cells for the treatment of ischemic stroke," Journal of the Neurological Sciences, vol. 265, no. 1-2, pp. 73-77, 2008.

[7] A. Hejčl, J. Šedý, M. Kapcalová et al., "HPMA-RGD hydrogels seeded with mesenchymal stem cells improve functional outcome in chronic spinal cord injury," Stem Cells and Development, vol. 19, no. 10, pp. 1535-1546, 2010.

[8] J. C. Ra, I. S. Shin, S. H. Kim et al., "Safety of intravenous infusion of human adipose tissue-derived mesenchymal stem cells in animals and humans," Stem Cells and Development, vol. 20, no. 8, pp. 1297-1308, 2011.

[9] F.-W. Wang, Z. Wang, Y.-M. Zhang et al., "Protective effect of melatonin on bone marrow mesenchymal stem cells against hydrogen peroxide-induced apoptosis in vitro," Journal of Cellular Biochemistry, vol. 114, no. 10, pp. 2346-2355, 2013.

[10] B. Sun, M. Feng, X. Tian et al., "Dl-3-n-Butylphthalide protects rat bone marrow stem cells against hydrogen peroxide-induced cell death through antioxidation and activation of PI3K-Akt pathway," Neuroscience Letters, vol. 516, no. 2, pp. 247-252, 2012. 
[11] M. Dong, W. Ding, Y. Liao et al., "Polydatin prevents hypertrophy in phenylephrine induced neonatal mouse cardiomyocytes and pressure-overload mouse models," European Journal of Pharmacology, vol. 746, pp. 186-197, 2014.

[12] Q. Zhang, Y. Tan, N. Zhang, and F. Yao, "Polydatin supplementation ameliorates diet-induced development of insulin resistance and hepatic steatosis in rats," Molecular Medicine Reports, vol. 11, no. 1, pp. 603-610, 2014.

[13] X. Xie, J. Peng, K. Huang et al., "Polydatin ameliorates experimental diabetes-induced fibronectin through inhibiting the activation of NF- $\kappa \mathrm{B}$ signaling pathway in rat glomerular mesangial cells," Molecular and Cellular Endocrinology, vol. 362, no. 1-2, pp. 183-193, 2012.

[14] L. Zhang, W.-F. Ma, J. Li et al., "Influence of processing on pharmacokinetic of typical constituents in radix polygoni multiflori after oral administration by LC-ESI-MS/MS," Journal of Ethnopharmacology, vol. 148, no. 1, pp. 246-253, 2013.

[15] J. Sun, Y. Qu, H. He et al., "Protective effect of polydatin on learning and memory impairments in neonatal rats with hypoxic-ischemic brain injury by up-regulating brain-derived neurotrophic factor," Molecular Medicine Reports, vol. 10, no. 6, pp. 3047-3051, 2014.

[16] K. Huang, C. Chen, J. Hao et al., "Polydatin promotes Nrf2-ARE anti-oxidative pathway through activating Sirt1 to resist AGEsinduced upregulation of fibronetin and transforming growth factor-betal in rat glomerular messangial cells," Molecular and Cellular Endocrinology, vol. 399, pp. 178-189, 2015.

[17] L. Chen, Z. Lan, Q. Lin et al., "Polydatin ameliorates renal injury by attenuating oxidative stress-related inflammatory responses in fructose-induced urate nephropathic mice," Food and Chemical Toxicology, vol. 52, pp. 28-35, 2013.

[18] X. Jiang, W. Liu, J. Deng et al., "Polydatin protects cardiac function against burn injury by inhibiting sarcoplasmic reticulum $\mathrm{Ca}^{2+}$ leak by reducing oxidative modification of ryanodine receptors," Free Radical Biology and Medicine, vol. 60, pp. 292299, 2013.

[19] W. Zhang, N. Liu, H. Shi et al., "Upregulation of BMSCs osteogenesis by positively-charged tertiary amines on polymeric implants via charge/iNOS signaling pathway," Scientific Reports, vol. 5, article 9369, 2015.

[20] D. Cizkova, S. Devaux, F. Le Marrec-Croq et al., "Modulation properties of factors released by bone marrow stromal cells on activated microglia: an in vitro study," Scientific Reports, vol. 4, article 7514, 2014.

[21] Y. Huang, J. Qin, M. Chen et al., "Lithium prevents acroleininduced neurotoxicity in HT22 mouse hippocampal Cells," Neurochemical Research, vol. 39, no. 4, pp. 677-684, 2014.

[22] M. Chen, M. Tan, M. Jing et al., "Berberine protects homocysteic acid-induced HT-22 cell death: involvement of Akt pathway," Metabolic Brain Disease, vol. 30, pp. 137-142, 2015.

[23] D. Su, Y. Cheng, M. Liu et al., "Comparision of piceid and resveratrol in antioxidation and antiproliferation activities in vitro," PLoS ONE, vol. 8, no. 1, Article ID e54505, 2013.

[24] Y. Zhang, Z. Zhuang, Q. Meng, Y. Jiao, J. Xu, and S. Fan, "Polydatin inhibits growth of lung cancer cells by inducing apoptosis and causing cell cycle arrest," Oncology Letters, vol. 7, no. 1, pp. 295-301, 2014.

[25] M. J. Calkins, D. A. Johnson, J. A. Townsend et al., "The Nrf2/ARE pathway as a potential therapeutic target in neurodegenerative disease," Antioxidants \& Redox Signaling, vol. 11, no. 3, pp. 497-508, 2009.
[26] X.-J. Chao, Z.-W. Chen, A.-M. Liu et al., "Effect of tacrine3-caffeic acid, a novel multifunctional anti-alzheimer's dimer, against oxidative-stress-induced cell death in HT22 hippocampal neurons: Involvement of Nrf2/HO-1 pathway," CNS Neuroscience \& Therapeutics, vol. 20, no. 9, pp. 840-850, 2014.

[27] D. Ren, N. F. Villeneuve, T. Jiang et al., "Brusatol enhances the efficacy of chemotherapy by inhibiting the Nrf2-mediated defense mechanism," Proceedings of the National Academy of Sciences of the United States of America, vol. 108, no. 4, pp. 14331438, 2011.

[28] M. F. Pittenger, A. M. Mackay, S. C. Beck et al., "Multilineage potential of adult human mesenchymal stem cells," Science, vol. 284, no. 5411, pp. 143-147, 1999.

[29] D. J. Prockop, "Marrow stromal cells as stem cells for nonhematopoietic tissues," Science, vol. 276, no. 5309, pp. 71-74, 1997.

[30] J. Qiu, P. Shi, W. Mao, Y. Zhao, W. Liu, and Y. Wang, "Effect of apoptosis in neural stem cells treated with sevoflurane," BMC Anesthesiology, vol. 15, article 25, 2015.

[31] E. A. Slee, M. T. Harte, R. M. Kluck et al., "Ordering the cytochrome c-initiated caspase cascade: hierarchical activation of caspases-2, $-3,-6,-7,-8$, and -10 in a caspase-9-dependent manner," The Journal of Cell Biology, vol. 144, no. 2, pp. 281-292, 1999.

[32] R. M. Abdelsalam and M. M. Safar, "Neuroprotective effects of vildagliptin in rat rotenone Parkinson's disease model: role of RAGE-NFkappaB and Nrf2-antioxidant signaling pathways," Journal of Neurochemistry, vol. 133, no. 5, pp. 700-707, 2015.

[33] A. Yanaka, S. Zhang, M. Tauchi et al., "Role of the nrf-2 gene in protection and repair of gastric mucosa against oxidative stress," Inflammopharmacology, vol. 13, no. 1-3, pp. 83-90, 2005.

[34] L. Wang, R. Wang, M. Jin et al., "Carvedilol attenuates 6hydroxydopamine-induced cell death in PC12 cells: involvement of Akt and Nrf2/ARE pathways," Neurochemical Research, vol. 39, pp. 1733-1740, 2014. 

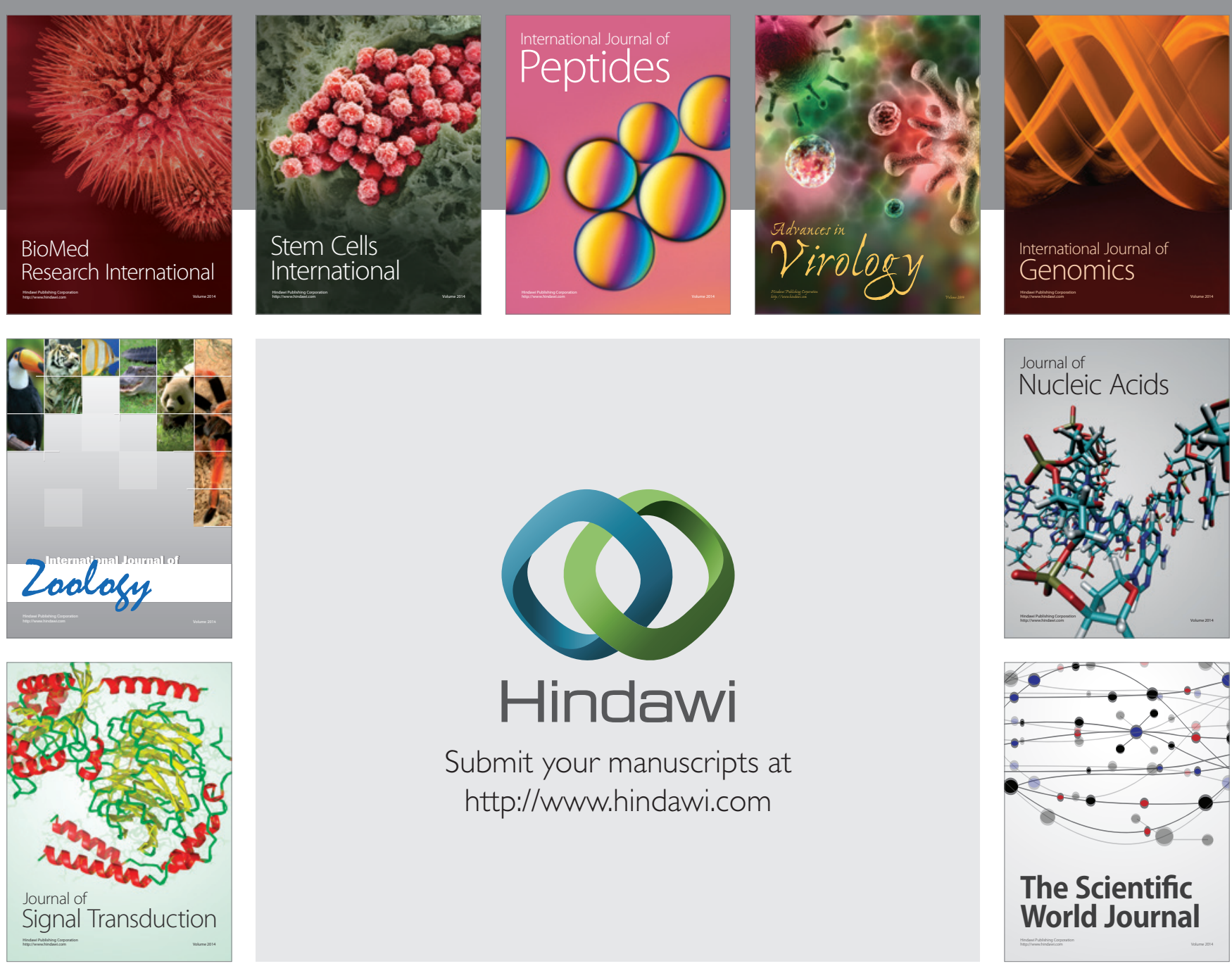

Submit your manuscripts at

http://www.hindawi.com
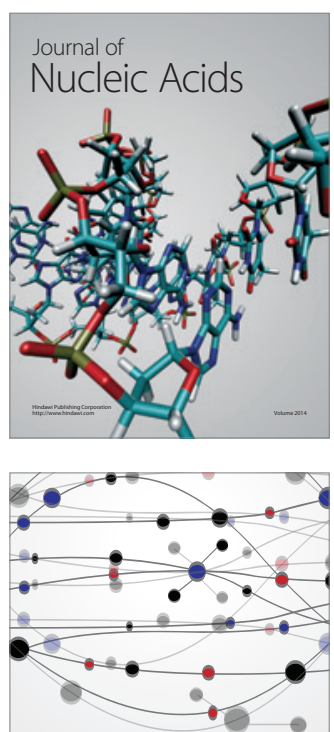

The Scientific World Journal
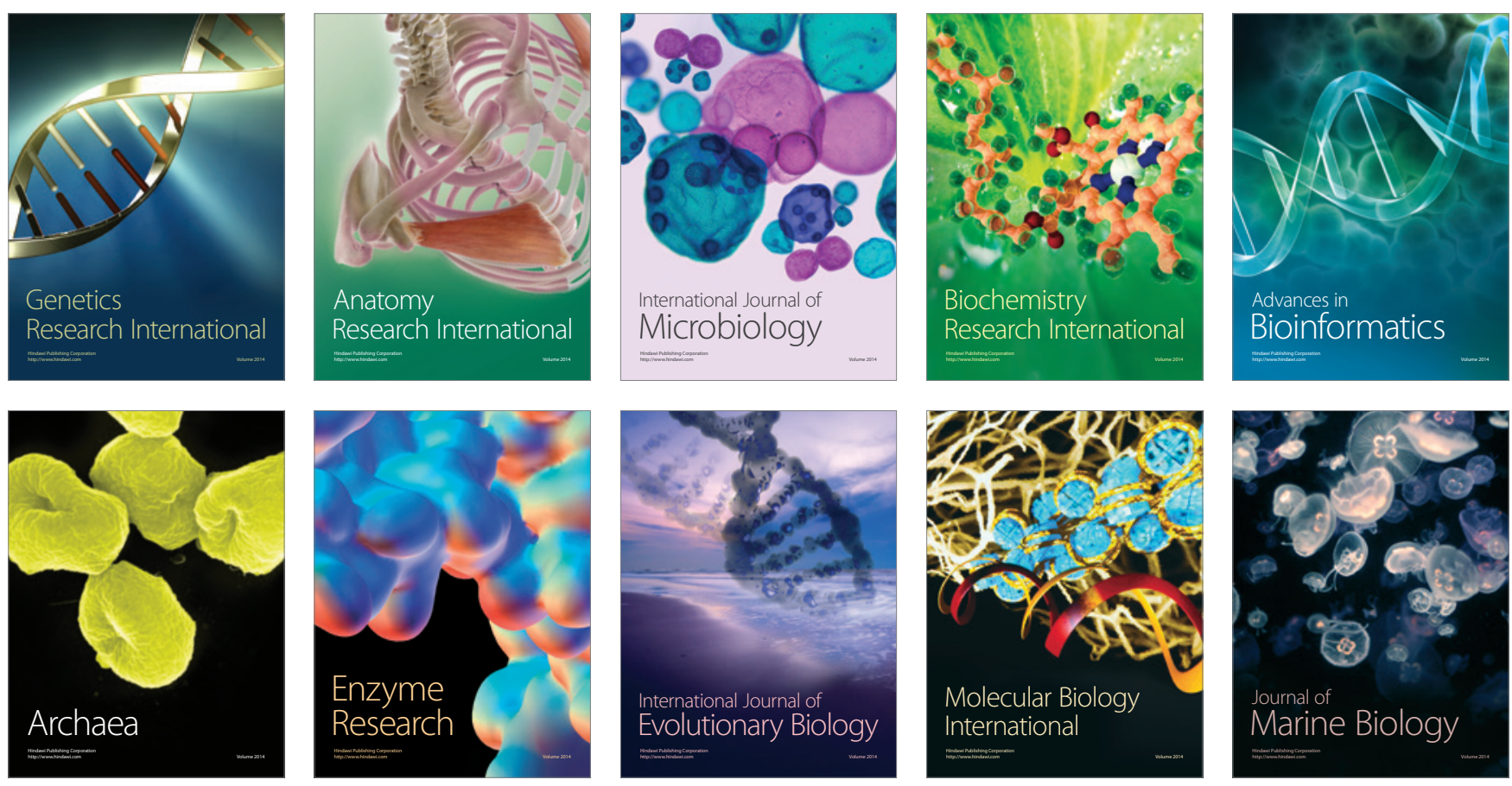